\title{
El antiguo templo del convento de San Miguel de las Victorias de La Laguna
}

\author{
The old temple of the convent of San Miguel de las \\ Victorias de La Laguna \\ Cristian MARRERO BRITO \\ cristianmarrerobrito@outlook.com \\ DOI: http://dx.doi.org/10.18002/da.v0i18.5627
}

Recibido: 3-XII-2018

Aceptado: 10-VII-2019

RESUMEN: En la isla de Tenerife, en el archipiélago canario, los franciscanos han custodiado durante siglos una imagen de gran valor artístico que goza de una ferviente devoción, el Cristo de La Laguna. Esta se forja en el siglo XVI y dio lugar a innumerables donaciones y la construcción de un inmenso patrimonio. La mayor parte de este desapareció en el incendio del año 1810. En él se perdió el templo con toda la decoración existente salvándose únicamente la imagen y los elementos de plata. En el siguiente artículo nos proponemos hacer una reconstrucción del aspecto que tenía la iglesia justo antes de desaparecer gracias a la documentación custodiada por su cofradía, la Esclavitud del Cristo de La Laguna.

Palabras clave: Cristo de La Laguna; Plata; Órgano; Tenerife; Pinturas murales.

ABSTRACT: On the island of Tenerife, in the Canary archipelago, the Franciscans have guarded for centuries an image of great artistic value that enjoys a fervent devotion, the Christ of La Laguna. This was forged in the sixteenth century and resulted in innumerable donations and the construction of an immense heritage. Most of this disappeared in the fire of the year 1810. The temple was lost in it with all the existing decoration except for this image and the silver elements. In the following article we propose to make a reconstruction of the aspect that the church had just before disappearing thanks to the documentation guarded by the Slavery of the Christ of La Laguna.

Keywords: Cristo de La Laguna; Silver; Organ; Tenerife; Mural paintings.

\section{INTRODUCCIÓN}

La ciudad de La Laguna fue durante los primeros siglos inmediatamente después de la conquista uno de los puntos neurálgicos del Archipiélago. Esta relevancia, que provenía principalmente del floreciente comercio en un principio con Flandes y posteriormente con el Nuevo Mundo y la Península, se tradujo en la construcción de una ciudad acorde a tal importancia. Lógico es que esta suntuosidad se transmitiera a los templos.
Gran parte de los ingresos se vieron destinados a la expiación de los pecados de sus donantes, mediante el pago de obras de arte que acabaron embelleciendo los templos.

La iglesia gozaba de una importante presencia en la ciudad. A las dos grandes parroquias debemos sumar los numerosos templos que se levantaban en el exterior del núcleo urbano y múltiples capillas, como las de la Cruz, salpicando las calles del casco urbano. Pero destacaban especialmente los 
conventos que ocupaban grandes extensiones del terreno de la ciudad, manzanas completas en los lugares más destacados fueron ocupadas por franciscanos, dominicos, en sus versiones masculina y femenina, y agustinos. Más de una decena de edificios religiosos que dominaban el espacio público de la capital de la isla y que obtuvieron un gran desarrollo, pero en uno de ellos residía un símbolo de identidad de la población.

Los franciscanos llegaron a Tenerife de la mano de Alonso Fernández de Lugo, en la conquista ${ }^{1}$. Según los relatos de la época, los llevó consigo para atender las necesidades de las tropas y adoctrinar a la población prehispana. Terminada la conquista se retiraron a un cerro, hasta la cesión de los terrenos para la construcción del convento ${ }^{2}$. La fundación del cenobio se realizó con cinco frailes de los cuales conocemos sus nombres: fray Juan Campuzano, fray Francisco Pérez, fray Juan de Soria, fray Juan de Villadiego y Fray Gonzalo. En el año 1500 se les concedieron las tierras del entorno de la ermita de San Miguel de las Victorias, que no fueron utilizados por presentar molestias para los frailes, que tenían que cruzar el arroyo que les separaba de la ciudad. Por ello en el año 1505 se les dieron los actuales terrenos, en los que un año después dio comienzo la construcción.

Largo fue el proceso de construcción de un complejo de tales dimensiones, sobre todo si tenemos en cuenta la pobreza de la orden, dependiendo entonces de las limosnas. La imagen del Cristo de La Laguna no

${ }^{1}$ Probablemente los franciscanos llegados a Canarias fueran observantes. Existe un interesante artículo que trata esta cuestión: Hipólito Sancho de Sopranis, "Los conventos franciscanos de la misión de Canarias (1443-1487)", Anuario de Estudios Atlánticos, nº 5 (1959), 375-397.

\footnotetext{
${ }^{2}$ Buenaventura Bonnet y Reverón realizó un buen estudio sobre este primer templo desaparecido, es el que hemos utilizado para extraer los datos recogidos sobre la cesión de los terrenos y su construcción, en su libro titulado El Santísimo Cristo de La Laguna y su culto (Santa Cruz de Tenerife: Cabildo insular de Tenerife, 1985).
}

había llegado, por lo que no contaban con la solvencia económica que su devoción les suministró. Entre los años de 1506 y 1515 se realizaron todas las obras, quedando partes por concluir, como el templo. Para la construcción de la casa franciscana se utilizó la piedra del peñol. Los múltiples esfuerzos que realizaron les sirvieron para tener el tan ansiado complejo, pero lejos estaban de permanecer en paz.

Las calamidades marcaron la vida de la comunidad. En 1546 la orden abandonó el edificio para ser ocupado por la congregación franciscana femenina que se funda en la isla, bajo el patronazgo de Santa Clara de Asís. Los frailes se desplazaron hasta el hospital de San Sebastián de la misma ciudad, pero dejaron atrás todo lo que habían forjado en los primeros y duros años, incluida la venerada imagen del Cristo de La Laguna. Tras treinta años la comunidad masculina recurrió a la mediación del papa para hacer que se les devolviera el convento. En el año 1577 regresaron a su primitiva casa, cumpliéndose el sueño de los frailes.

La lista de incidencias sigue en el año 1713, cuando un aluvión dañó el convento. Estos fenómenos climatológicos, habituales en Tenerife a lo largo de los siglos, dejaban considerables destrozos. Los daños de la casa llevaron a los padres seráficos a un nuevo exilio en San Sebastián. Pero la fecha más negra es el año 1810, año en el que el conjunto sufrió un incendio que destruyó la iglesia y parte del convento.

\section{LA DECORACIÓN DEL TEMPLO}

A mediados del siglo XVIII se puso en marcha un complejo proceso de embellecimiento del interior de la iglesia, cuando se acaban las obras estructurales de la capilla mayor. No obstante, conviene señalar que prácticamente en las mismas fechas en la ciudad de La Laguna, también en diferentes puntos del archipiélago, se dieron distintos ejemplos de reformas inspiradas en postulados ilustrados. Fueron los casos de la Parroquia de Nuestra Señora de Los Re- 
medios o la Parroquia de Nuestra Señora de La Concepción ${ }^{3}$. En el mes de diciembre del año 1746 se comenzó a forrar las paredes de la capilla mayor con madera, que posteriormente fue tallada y dorada, a la par que el retablo de la misma, por lo que en dicho año debía estar terminada la obra de ampliación del templo ${ }^{4}$. Es la primera acción de embellecimiento que se realizó y no se hizo de una vez, por el gran costo que suponía y el tiempo necesario; por ello nos encontramos en el año siguiente pagos de la misma índole. En el año 1747 también se comenzó la obra del púlpito que aparece en la documentación: "Por más un púlpito con su sombrero a fin del servicio del Santísimo Cristo" ${ }^{\text {. La pieza }}$ se terminó en los años posteriores al 1761, con el dorado del púlpito, respaldar, cartelas del remate y las escaleras. Por esta misma fecha debe de haberse comenzado el retablo mayor, en el que se entronizaba la imagen del Santísimo Cristo. El retablo corresponde con el actual, pero lo trataremos posteriormente, cuando nos dediquemos a las alhajas de plata del templo. Al haberse realizado si-

\footnotetext{
${ }^{3}$ Este tema ha sido ampliamente tratado por Juan Alejandro Lorenzo Lima, "Arquitectura, ilustración e ideal eucarístico en los templos de Canarias (17551850)" (tesis doctoral, Granada, 2010), 500-526 y 551600.

${ }^{4}$ Existía una discusión sobre en las fechas de este suceso. Tarquis lo ubicó en el año 1744 a partir de un documento del cronista Anchieta y Alarcón que el mismo transcribe y del que no se tienen más noticias. Sin embargo, Bonnet y Reverón traslada la dispensa del Cabildo once años después. En el libro I de Mayordomía hemos encontrado el registro de este pago en el año 1746. Se corrobora así que la fecha real de la construcción de la capilla mayor es la aportada por Pedro Tarquis a través del testimonio de Anchieta y Alarcón. Archivo de la Esclavitud del Santísimo Cristo de La Laguna (AESCDLL), Libro I de Mayordomía, Aumentos de Juan Mireles, 1746, s.f.; Buenaventura Bonnet y Reverón, El Santísimo Cristo de La Laguna y su culto (Santa Cruz de Tenerife: Cabildo insular de Tenerife, 1985), 118-119.; Pedro Tarquis, El Cristo de La Laguna y su santuario (La Laguna: Real y Venerable Esclavitud del Santísimo Cristo de La Laguna, 2008), 143-144.
}

${ }^{5}$ AESCDLL, Libro I de Mayordomía, Aumentos de Juan Sánchez, 1747, s.f. multáneamente podrían presentar un aspecto cercano al del púlpito.

Afortunadamente se salvaron del incendio que asoló al templo en el año 1810 el púlpito y el retablo, no así las piezas talladas que se encontraban a los lados de este último. El púlpito no se ha incorporado al templo actual y se conserva despiezado en las dependencias anexas al mismo. La escalera es la única de las partes que no se pudo salvar. Dicho púlpito corresponde estilísticamente con los últimos coletazos del rococó. La curva y la contracurva cobran una especial importancia en la obra, especialmente en el respaldar. Las decoraciones a base de "S", tan características del momento, salpican todas las partes del conjunto, al igual que ocurre con el componente vegetal. Los lugares carentes de escultura fueron cubiertos a base de decoraciones pintadas con motivos florales. Tanto en la copa como en el astil se repiten formas frutales, con abultada talla. Esta intrusión de la naturaleza está muy en sintonía con el gusto dieciochesco, como también lo está la utilización del abundante oro en la obra, pero más evidente es la gama cromática que abarca desde los rojos y verdes más intensos hasta los tonos pastel, al más puro estilo francés. Coinciden en los motivos ornamentales, y en la utilización del color rojo $\mathrm{y}$ verde, con la parte interior de la hornacina del Cristo, por lo que no solo el dorado y policromado debe ser del mismo autor sino también la talla.

La otra gran aportación al enriquecimiento del templo se hace en los muros. Los franciscanos articularon un complejo conjunto pictórico para llenar las paredes del templo, completando así la labor decorativa. No es algo habitual en las islas, no al menos con la dimensión que se le dio en este lugar. Lamentablemente todas fueron pasto de las llamas en los sucesos del año 1810, por lo que no podremos acercarnos al estilo que tenían. Por otro lado, la documentación al respecto es casi nula; algunos cronistas dieron noticias muy puntuales sobre dichas pinturas murales, sin entrar en detalles ni aportar da- 
tos de importancia ${ }^{6}$. En los libros de cuentas de la mayordomía están referidas cada una de las pinturas que se realizaron y cuál fue su costo, en materiales y oficiales, además se especifica la iconografía, aunque no existen tampoco noticias al respecto de los autores.

Las características de esta intervención la ponen en relación con el gusto de la Ilustración, pudiendo tratarse de las primeras manifestaciones de este tipo en las islas. Una de las primeras acciones consistió en tapar las armaduras de madera con tablazones y acabados clasicistas, eliminando los mal mirados artesonados, símbolo de un periodo que no era del gusto de los ilustrados. Así lo cuentan en los libros de mayordomía: “Encañisoce la capilla mayor se dio de yeso con cuchara y pluma a todo su techo, con molduras de madera, jaspeadas de azul"7. No hay que olvidar que el movimiento ilustrado en Canarias empezó oficialmente años después de estas obras. La Real Sociedad Económica de Amigos del País de La Laguna se creó en el año 1776 cuando, tras haber creado la de Las Palmas, el Obispo Cervera viajó al resto de islas para repetir la acción. No obstante, los ilustrados de Tenerife defendieron su mayor antigüedad, lo que no es cierto, pero sí es verdad que fue la primera que expresó la voluntad de tener una de estas instituciones, como relata Van de Walle de Cervellón en el año 1775. Hasta en tres ocasiones escribió sobre las ventajas que tendría para la isla contar con una institución como ya tenían en el País Vasco y en Madrid ${ }^{8}$. Estas fundaciones corresponden sin duda a un sentimiento

\footnotetext{
${ }^{6}$ Recientemente han sido recogidas someramente en Carlos Rodríguez Morales, Todo es de plata. Las alhajas del Cristo de La Laguna (La Laguna: Ayuntamiento de San Cristóbal de La Laguna, 2016), 25.
}

${ }^{7}$ AESCDLL, Libro I de Mayordomía, Aumentos de Manuel Almeda, 1757, s. f.

${ }^{8}$ Manuel Rodríguez Mesa y Francisco J. Macías Martín, Materias útiles: datos para la historia de su aprovechamiento en la agricultura, el comercio y las artes de Tenerife durante los siglos XV-XVIII, la Real Sociedad Económica de Tenerife impulsadora de renovación y del progreso (San Cristóbal de La Laguna: Real Sociedad Económica de Amigos del País de Tenerife, 2012), 172. que se venía gestando en los tiempos en los que se producen las reformas del interior de la iglesia de los franciscanos.

En cuanto al repertorio pictórico que tuvo la iglesia, la capilla mayor fue la que más pinturas concentraba. De nuevo vemos cómo se volvieron a incluir imitaciones de jaspe para los arcos, figuras que imitan estar realizadas en mármol, motivos de ascendencia clásica que hablan de la vuelta al clasicismo en Canarias. Sobre esta capilla se dice lo siguiente en los libros de mayordomía: "Pintáronse al fresco todas las paredes de esta Capilla con estatuas imitando a mármol de las cuatro virtudes Religión, Pobreza, Obediencia y Castidad. Las de los cuatro profetas mayores, y los cuatro evangelistas [...] Pintáronse los dos arcos colaterales con albayalde al óleo imitándose jaspe [...] Pintose el arco mayor en el mismo modo sobre cal al fresco a N.S ${ }^{\text {a }}$. De los Dolores con el cuerpo de su santísimo hijo en los brazos, y en el demás ámbito las demás figuras e instrumentos pertenecientes al descendimiento de la cruz" Vemos pues como los franciscanos idearon a la perfección el discurso iconográfico del templo, ubicando en el lugar más importante a las más altas personalidades, evangelistas y profetas, y las virtudes. Cerraban el conjunto la madre con el hijo en brazos y los elementos de la pasión, concordando con el carácter penitencial de la capilla, que estaba presidida por el milagroso crucifijo.

El templo contó aún con otros dos conjuntos iconográficos. El siguiente estaba dispuesto en la nave del templo. Igual que en el caso anterior se tapó la techumbre de madera con cañizo de la siguiente manera: "enyesose y encañose al modo de la Capilla mayor todo el cielo de la nave"10. Aunque en esta ocasión no se haga referencia a la utilización de imitaciones en jaspe podemos suponer que se repetían, pues dice que se hicieron al

\footnotetext{
${ }^{9}$ AESCDLL, Libro I de Mayordomía, Aumentos de Manuel Almeda, 1757, s. f.

${ }^{10}$ AESCDLL, Libro I de Mayordomía, Aumentos de Manuel Almeda, 1757, s. f.
} 
modo de la capilla mayor. Las pinturas de la nave se ubicaron en los arcos que daban acceso a las capillas, concretamente en el espacio intermedio de los dos arcos y encima de estos, donde se pintaron las escenas del nacimiento de Cristo, la adoración de los Reyes, la institución del Santo Sacramento y la concesión del jubileo de Porciúncula ${ }^{11}$. Este último motivo es habitual en la iconografía de la orden franciscana, pues tiene relación con momentos claves de la congregación. En la pintura canaria no es habitual encontrar representaciones con este motivo. Debemos poner en relación esta escena con la pintura Comida en la Porciúncula del convento de Santa Clara de la misma ciudad, pues son las dos únicas referencias en el archipiélago. Los otros dos motivos también responden al repertorio seráfico, pues tienen relación con el padre de la orden, San Francisco de Asís, que tradicionalmente es considerado el creador del primer nacimiento o belén.

El último programa iconográfico estaba en el coro. Fue el espacio elegido para representar a la familia franciscana. Se pintaron los principales santos de la orden, alternando con escenas habituales de la misma. En el libro de mayordomía se describen de la siguiente manera: "Pintáronse las paredes del coro sobre cal al fresco los santos principales de la primera orden San Francisco las santas de la Seglar, santos y santas de la Tercera, y sobre la puerta del coro el Santo Patriarca suplicando para la confirmación de la regla, y sobre las puertas del órgano, el sepulcro con el cuerpo el N.S. Patriarca con la cripta de San Nicolás".

Pedro Tarquis recoge la información del cronista Anchieta y Alarcón, que da algunas noticias sobre las pinturas murales del templo, concretamente de una de las pinturas, que estaba debajo del órgano, en la que se representaba una sagrada familia con San Juan, San Francisco de Asís y Santo Domingo. El cronista cita textualmente las palabras del provincial de la orden, fray José, que de-

${ }^{11}$ AESCDLL, Libro I de Mayordomía, Aumentos de Manuel Almeda, 1757, s. f. cía haber llevado esta pintura mural desde la capilla de los Gallinatos, por lo que no debe corresponder con el fresco la misma iconografía que se realizó en los arcos de las naves $^{12}$. También recogió la realización de arquitecturas fingidas. Tarquis intenta dar luz acerca de la posible autoría de las pinturas. Sin llegar a evidencias claras plantea la posibilidad remota de pintores como Juan de Miranda o Francisco de Rojas y Paz; por entonces el primero se encontraba en la isla de Tenerife, pero eso solo podría probar la autoría de las pinturas realizadas sobre el año de 1757. Este tipo de trabajos se realizaban a lo largo de largos periodos, por lo que es poco probable que fueran hechas todas por un solo artífice.

En los últimos años de la década de los sesenta del siglo XVIII se realizaron aún algunas obras más. En primer lugar, se modificó notablemente la imagen de la capilla de Juana Jerónima, que desde su fundación cumplió las funciones de capilla sacramental. La renovación se centró en el retablo, como podemos ver en la siguiente nota: "Fabricose un Retablo para la capilla del Sagrario y se colocaron en los tres nichos del primero cuerpo a N.Sa. de los Dolores S. Juan evangelista y la Magdalena y en el segundo cuerpo se colocaron tres quadros el uno de la Asuncion, otro del Santo San Juan Bautista y el Santo San Bernardo"13. No se menciona nada del dorado de la pieza, ni en esta referencia, ni en los años que restan hasta que sucediera el incendio, por lo que no sabemos si se llegó a completar el conjunto antes de 1810.

\section{EL ÓRGANO DEL CONVENTO}

Un templo de esta magnitud requería aún de un último elemento. La música fue uno de los componentes primordiales de la

\footnotetext{
${ }^{12}$ Información recogida por Tarquis en su repaso sobre la pintura del convento. Tarquis, El Cristo de La Laguna..., 65-69.
}

${ }^{13}$ AESCDLL, Libro I de Mayordomía, Aumentos de Manuel Almeda, 1757, s.f. 
liturgia, más aún en un templo clave para el pueblo lagunero. En Canarias se conservan notables ejemplos de órganos exportados desde diversas partes de Europa que, últimamente, se han restaurado y puesto en funcionamiento de nuevo. En el año 1730 se dieron "cuatrocientos reales para ayuda de la fábrica del órgano nuevo de que cuidó $F$. Joseph Sanches"14; al hablar de "nuevo" podemos suponer que con anterioridad hubo otro órgano. Las obras de mejora que se realizaron en esta época, con motivo de los daños del aluvión, motivaron la sustitución del primitivo órgano, sin contar con noticias de cuál fue su destino.

Antes de la llegada del instrumento se modificó la tribuna del coro, que fue sustituida por otra, preparada para asentar sobre ella el nuevo órgano, aunque no se tienen noticias de dicha obra hasta el año 1770. Es posible que el número de obras que se estaban realizando en el momento impidiera afrontar los enormes costos que supuso traer un órgano desde Hamburgo. Por fin en este año se cuenta ya con el órgano que vino por mano de Thomas Ruz y costó 11763 reales, más otras cantidades menores aportadas por la Esclavitud y las provenientes de las mandas testamentarias de don Francisco Linares. No aparecen reflejadas en las cuentas el alcance de esas cantidades aportadas por la cofradía y las mandas testamentarias de don Francisco Linares por lo que no sabemos cuál fue el precio final del órgano. En el precio iban incluidas algunas piezas que tuvieron que ser realizadas a la carta en la isla ${ }^{15}$, por lo que suponemos que no llegó con las características que requirieron los frailes. Se explicaría así que tan solo dos años después de su llegada se realizaran amplios trabajos de mejora del instrumento por valor de otros 6300 reales. Las mejoras que se realizaron fueron las siguientes: "El órgano que se trajo de Hamburgo se desbarató para poner

${ }^{14}$ AESCDLL, Libro I de Mayordomía, Aumentos de Juan Mireles, 1730, s. f.

${ }^{15}$ AESCDLL, Libro I de Mayordomía, Aumentos de Manuel Almeda, 1770, s.f. el pedal en la mano, se hizo caja nueva, el secreto, el fuelle, el registro de clarín, el de trompetas, el de cornetas, medio registro de la octava tapada, y a cada registro dos caños más; y últimamente se desmontó, y desbarató el secreto para reparar la falta de pasar el viento por haberse empeorado; se replanaron todas sus piezas, se limpió la cañería, se levantó registro tapado de palo, se le pusieron arriostes correspondientes de bigotes y tijeras y se logró el quedar perfectamente seguro y ha sido su costo de todo seis mil y trecientos reales" ${ }^{\prime \prime}$.

\section{LOS OBJETOS DE PLATA}

Otro de los elementos definitorios de la imagen que este templo tuvo en el siglo XVIII, y que en parte se sigue manteniendo, es la plata. Desde antes de la fundación de la Esclavitud, en el año 1659, se había consolidado la tradición que unía la imagen del Santísimo Cristo con los ornamentos de plata. Son los obsequios del pueblo lagunero, que siempre se sintió en deuda por los grandes favores recibidos. Así se fue configurando la estética de la capilla mayor, transformándola en un recinto brillante y resplandeciente, donde todos los elementos estaban realizados con el preciado metal. Es algo que afortunadamente podemos seguir admirando, puesto que muchos de estos elementos sobrevivieron al incendio de $1810 \mathrm{y}$ la devoción del Cristo de La Laguna ha mantenido esta tradición.

Los devotos del Santísimo Cristo surtieron a la imagen de un numeroso conjunto de elementos de plata, especialmente objetos para iluminar el templo. Cierto es que en este tiempo se adquirieron especialmente piezas textiles, como lo demuestran los ocho doseles usados, cuatro pequeños y cuatro grandes, los dos grandes nuevos y un sinfín de ternos y velos para colocar a la imagen. Pero se realizan algunas piezas de plata como las primeras andas de salida, que fue-

${ }^{16}$ AESCDLL, Libro I de Mayordomía, Aumentos de Antonio José Miguens, 1772, s.f. 
ron donadas por Lázaro Rivero de Escobar en 1654. En la misma fecha documentamos seis lámparas de plata que fueron donadas por el que fuera provincial de la orden en Canarias, y profundo devoto del Cristo de La Laguna, Fray Luis de Quirós. Estas lámparas tuvieron que ser arregladas tan solo dos años después por "estar muy mal tratados"17. Todos estos bienes pasaron a manos de la Esclavitud tras su fundación, con la condición que fueran usados para el culto de la sagrada imagen. Posteriormente se realizaron nuevas piezas, como los ciriales de plata que fueron costeados a medias por don Pedro Carrillo de Guzmán, Capitán General de Canarias, y Fray Bernabé Castillo.

Una de las piezas más significativas, dentro del repertorio de alhajas del Cristo, fueron los blandones de plata realizados en el año 1664: “Unos blandones grande (sic) de plata que hizo la cofradía que costaron de plata y manos diez y seis mil reales con un bastón así mismo de plata con que gobierna las procesiones el Esclavo mayor. Hízose esta obra por solicitud de Fray Juan de Francisco, siendo compañero de mayordomo que lo era entonces el señor don Alvarado Bracamonte, el cual y el don Pedro de Velasco diputado hicieron mucho en esta grande obra prestando grandes cantidades de dinero y plata para ella. Hicieron esta obra en este convento los Maestros Juan Roberto y Agustín de Soria en el año de 1664"18. Los blandones se acondicionaron en el año $1743^{19}$, por encontrarse en mal estado. Se les hizo "cubos y caretas" nuevas labradas en plata. También se sustituyeron las bases por unas nuevas, también de plata. Tuvo de todo costo la obra 750 reales. Lamentablemente se pierde el rastro de estas piezas, por lo que pensamos que debieron desaparecer en el incendio del año

${ }^{17}$ AESCDLL, Libro I de Mayordomía, Memoria de las alhajas que tiene el cristo de La Laguna, 1654, s. f.

${ }^{18}$ AESCDLL, Libro I de Mayordomía, Memoria de las alhajas que tiene el cristo de La Laguna, 1664, s. f.

${ }^{19}$ Han sido incluidos recientemente en Rodríguez Morales, Todo es de plata..., 53-54.
$1810^{20}$. En la Laguna, los templos más destacados también contaron con obras similares; en la Catedral se conserva una pareja ${ }^{21}$, que nos pueden ayudar a hacernos una idea de la imagen que debieron presentar los del convento.

Del año 1630 data la primera cruz de plata, que aún se utiliza para colocar la imagen en el retablo. Fue regalada por Francisco Bautista Pereira de Lugo. En ese año fue proveedor de la fiesta de septiembre, por ello mandó forrar con placas de plata la cruz en la que salía la imagen, trabajo que realizó el platero Antonio Alpoin. Figura en la parte inferior de la pieza una inscripción en la que se recoge toda esta información. La cruz carece del revestimiento de plata en su parte trasera. Rodríguez Morales sugiere que pudiera estar así desde su creación, pues en dichas fechas la imagen salía cubierta con un velo en la parte posterior. Sin embargo, gracias a la información recientemente encontrada sabemos que no fue así. Las placas traseras de esta cruz fueron retiradas en el año 1686. Se reutilizaron, junto con las placas de la primera base procesional, para la elaboración de seis candeleros que realizó Roberto Zambrana ${ }^{22}$.

${ }^{20}$ AESCDLL, Libro I de Mayordomía, Aumentos de Juan Mireles, 1743, s. f.

${ }^{21}$ Alberto Darias Príncipe y Teresa Purriños Corbella, Arte religión y sociedad en Canarias. La Catedral de La Laguna (La Laguna: Ayuntamiento de La Laguna, 1997), 178-179; Jesús Pérez Morera, “El patrimonio suntuario de la parroquia", en Patrimonio e historia de la antigua Catedral de La Laguna, coord. por Juan Alejandro Lorenzo Lima (San Cristóbal de La Laguna: Diócesis y Cabildo Catedral de San Cristóbal-Gobierno de Canarias-Cabildo de Tenerife-Ayuntamiento de San Cristóbal-Fundación Caja Canarias, 2013), 47.

${ }^{22}$ Así se hace constar en el libro de mayordomía: "Ytten más se han hecho seis candeleros de plata del tamaño de la que igualdad de los seis que tenía la cofradía y han llevado todos sin cuarenta y nueve marcos y medios que hacen onzas cuatrocientas y setenta y seis. $Y$ otra obra se ha hecho con la plata que tenía la peana vieja que tenía el santísimo Cristo antes que hubiera lo que tiene y con láminas de la plata que tenía la cruz y la otra mitad quedo clavada en la misma cruz que está en el nicho en que está la Santísima imagen, y habiendo pesado 
La segunda cruz de salida es la que aún se sigue utilizando en la solemnidad del 14 de septiembre. Hernández Perera la catalogó como pieza de procedencia canaria del siglo XVIII ${ }^{23}$. Sin embargo, gracias a las recientes aportaciones de Rodríguez Morales sabemos que fue realizada en el año 1684 por el mismo maestro platero, Juan Roberto Zambrana ${ }^{24}$. La primera de las cruces de plata solo presentaba un recubrimiento de planchas con una decoración plana, con motivos geométricos y botonadura. La pieza de Juan Roberto tiene una decoración más profusa y con un mayor relieve, inspirándose principalmente en motivos de carácter vegetal. Este mismo investigador ha fechado las cantoneras de la segunda cruz y el inri en el año 1737. Pero en el inri se puede leer una inscripción que dice: "Restaurado el anverso y hecho el reverso por Juan Ángel Glez septiembre de 1999". No sabemos si intervino también las cantoneras, pero es probable.

La base procesional del Cristo, también de plata, ha sido reconocida por los investigadores como la donada por el capitán Lázaro Rivero en el año $1654^{25}$. Rodríguez Morales ya adelantó que dicha pieza fue

el mismo Juan Roberto toda la plata de la peana y media cruz, según consta en su firma que está en el cuaderno viejo, halló haber pesado quinientos y setenta y dos onzas, con que rebajaba otras cuatrocientas y setenta y seis onzas, pesan noventa y seis onzas de plata. Se pagó al mismo Juan Roberto el marco a veinte y dos reales, con otro resto que importaron seiscientos y sesenta y ocho y el resto queda, que le debía al maestro Juan Roberto que son quinientos treinta y dos reales los han suplido los devotos y la solicitud hecho mía Ss Señor Sebastián Sanavia que esta obra se hizo febrero en 1685 agosto de 1686". AESCDLL, Libro I de Mayordomía, Aumentos de Sebastián Sanavia, 1686, s. f.

23 Jesús Hernández Perera, Orfebrería en Canarias (Madrid: Instituto “Diego Velázquez” CSIC, 1955), 277.

${ }^{24}$ Carlos Rodríguez Morales, Las cruces de La Laguna. Fiestas, capillas y tradición (San Cristóbal de La Laguna: Ayuntamiento de La Laguna, 2015), 25-28.

${ }^{25}$ Hernández Perera, Orfebrería..., 277; Francisco José Galante Gómez, El Cristo de La Laguna. 500 años de historia (San Cristóbal de La Laguna: Ayuntamiento de La Laguna, 2014), 162. solo la primera y que años después se realizó una nueva para sustituirla. Según estas informaciones la pieza se ejecutó por mano del mismo Juan Roberto Zambrana en el año 1684, teniendo por modelo unos dibujos del afamado pintor Cristóbal Hernández de Quintana y siendo la parte de carpintería y el clavado de Antonio Francisco de Orta ${ }^{26}$. Efectivamente hemos encontrado la misma información en el Libro de Mayordomía de la Esclavitud. El mismo investigador en publicaciones recientes apuntó cómo esta obra fue ampliada a lo largo del tiempo, aunque mantiene que hasta el año 1740 permaneció igual $^{27}$. Nosotros proponemos adelantar esta fecha hasta el año 1703, en el que encontramos la siguiente anotación: "se aumentaron tres gradas para el trono del santísimo Cristo con que quedó acabado para cuando se baja del nicho, hicieron de todo costo dichas tres gradas con plata hechura, madera para las [...] y para la tarima del suelo, herraje, oficiales y costó para los que clavaron en la celda de cinco mil quinientos con cuarenta un reales, de la cual cantidad suplió el señor esclavo mayor, que lo fue el señor Marques de Zelada D. Diego Benítez de Lugo, el año de 1703, tres mil y veinte reales en la plata que suplió y la cofradía la plata que faltó, la hechura y lo demás dos mil quinientos y treinta y uno, como todo consta en el libro de gastos del dicho año de mil setecientos tres $^{\prime 28}$. Por lo tanto, la pieza actual es el resultado de juntar las dos partes. Si observamos las distintas gradas podemos apreciar una clara diferencia entre el primer nivel, decorado con cuatro mecheros en las esquinas y la " $\mathrm{S}$ " en el interior, y los siguientes tres niveles, que forman juntos una sucesión de molduras convexa, cóncava y convexa rematadas las esquinas de las primeras por cuatro águilas. Los clavos utilizados para fijar las placas de plata en las dos partes son distintos y se puede apreciar la unión clara de las

\footnotetext{
${ }^{26}$ Rodríguez Morales, Las cruces..., 28.

${ }^{27}$ Rodríguez Morales, Todo es de plata..., 95.

${ }^{28}$ AESCDLL, Libro I de Mayordomía, Aumentos de
} Buenaventura Dávila, 1703, s. f. 
dos fases. La duda queda en si la ampliación de los tres niveles siguió también el modelo del pintor Cristóbal Hernández de Quintana o si por el contrario responden a un nuevo diseño, pues se realizó 19 años después.

En el año 1825 la base procesional sufrió las consecuencias de los numerosos traslados a los que se vio sometida para salvarla de la incautación, por parte del gobierno, de los bienes desamortizados de los conventos. Por ello, se relata en las actas la pérdida de algunos pedazos. Se designó a uno de los esclavos para que la mandara a componer de nuevo y preservar su integridad ${ }^{29}$. La obra se completó en el año 1965 con la incorporación de otros tres niveles al graderío, coronas de las águilas, faroles y candelabros de guardabrisas, además de los respiraderos del paso.

La hermandad tuvo, desde sus primeros años de existencia, un paso de la virgen, en su advocación de la Soledad; parece ser que las imágenes de San Juan y la Magdalena aún desfilaban en tronos separados. En el año 1769 lo hacían así, pues se hicieron "de madera y doráronse las dos pariguelas en las que sale San Juan y la Magdalena"30. Las tres tallas fueron trasladadas al convento de clarisas, de donde aún salen cada madrugada de Viernes Santo para acompañar al Cristo de La Laguna. Al igual que el paso del Cristo, también fue objeto de embellecimiento, para lo cual se dispuso recubrirlo de placas de plata. Se trataba de un trono con baldaquino y un sol bajo el que se ubicaba la imagen de la virgen. En el año de 1730 se comenzó a vestir de plata todo el conjunto; las labores se fueron haciendo de manera paulatina, siendo el sol lo que más se prolongó y la parte que más cantidad de plata precisó. En el año 1739 se terminó de cubrir de plata el sol y se comenzó a hacer lo propio con los pilares del baldaquino. En el año 1742 se registró el pago por la realización del nuevo

\footnotetext{
${ }^{29}$ AESCDLL, Libro I de Actas, F 122, 1825, s. f.

${ }^{30}$ AESCDLL, Libro I de Mayordomía, Aumentos de Manuel Almeda, 1769, s. f.
}

sol en madera de vinático, por haberse roto el anterior ${ }^{31}$.

Todo este patrimonio está relacionado con las salidas procesionales. Sin embargo, el Cristo llegó a poseer un gran patrimonio para su culto interno, aunque no todas las piezas han llegado a nuestros días, por el nefasto incendio de 1810. Entre todo destaca el exuberante retablo de plata, en el que se cobija la imagen durante todo el año. La pieza más antigua del retablo es el frontal de plata, realizado en el año 1676, costeado por Alonso de Nava Grimón y Alvarado-Bracamonte segundo Marqués de Villanueva del Prado, que fue el encargado de organizar la festividad del 14 de septiembre de ese año; siguiendo la costumbre adquirida por entonces, los encargados de los festejos hacían importantes donativos a la imagen. Su autoría era desconocida hasta que Rodríguez Morales aportó la información que nos posibilita conocerla ${ }^{32}$. Se dice en ese año que, siendo esclavo mayor Alonso de Llarena, se hizo "un frontal de plata que hizo el mismo Juan Roberto"33. Encabeza pues la larga lista de encargos que realizó el maestro, que creó las piezas más importantes del patrimonio de la imagen.

El resto del retablo se ha venido fechando en el año 1675, siguiendo el texto de su inscripción: “El Señor Don Mateo Velasco, siendo Esclavo mayor dio de limosna toda esta obra de plata del nicho del Santísimo Cristo año De 1675". Galante Gómez diferencia entre la orla del nicho, la original en su opinión, del remate de rocalla que lo culmina, que dataría de la reforma del siglo XVIII ${ }^{34}$. Rodríguez Morales recoge la información que hemos podido estudiar, pero la trató también como una reforma ${ }^{35}$. El rastreo

\footnotetext{
${ }^{31}$ AESCDLL, Libro I de Mayordomía, Aumentos de Juan Mireles, 1642, s. f.

${ }^{32}$ Rodríguez Morales, Todo es de plata..., 86.

${ }^{33}$ AESCDLL, Libro I de Mayordomía, Memoria de las alhajas que tiene el cristo de La Laguna, 1676, s. f.

${ }^{34}$ Galante Gómez, El Cristo de La Laguna..., 153-154.

${ }^{35}$ Rodríguez Morales, Todo es de plata..., 76-83.
} 
de estos datos nos ha llevado a la conclusión de que este retablo donado en 1675 fue el primero, siendo sustituido años después. Este tenía precisamente la forma que indica Galante Gómez, tan solo la orla y en el interior la santa imagen. Tras el aluvión de principios del siglo XVIII, por algún motivo, se decidió rehacer dicho retablo, e incorporarle el remate de rocalla. Lo cierto es que se partió de lo existente, se retiraron todas las placas de plata para volver a clavarlas de nuevo. De esta manera nos encontramos que en el año 1717 se dice: "compraronse setenta y cinco onzas de plata para proseguir con la obra de la orla", por lo que la obra fue comenzada con anterioridad. En el año 1730 se volvió a adquirir más plata para recubrir la orla del nicho del Cristo. En este mismo año se menciona el término de la obra: "acabose de vestir la orla del nicho de plata". Finalmente, entre los años 1760-1761 se realizó el remate de la orla del retablo clavando en él la plata del antiguo ${ }^{36}$.

El sagrario es otra de las piezas más antiguas que conforman el retablo. Data del año 1676, el mismo año en el que se realizó el frontal. Otros investigadores lo sitúan en fechas más tardías ${ }^{37}$. En el año 1730 se realizó una pequeña reforma que consistió básicamente en "fabricar la puerta de la urna en que se coloca y encierra Señor Sacramentado" $^{\prime 38}$. El universo de plata que conformaba la capilla mayor del templo se completaba con una sucesión de gradas de plata, que arrancaban desde el presbiterio terminando en el retablo del Santísimo Cristo. No realizaremos un seguimiento de la construcción de las mismas, pues es una labor que se realizó durante un amplio marco cronológico y podría ser tedioso para el lector. En 1671, el mismo año que se culmina la orla del retablo, se puso fin a los trabajos con la realización de la última grada del presbiterio. Toda

${ }^{36}$ AESCDLL, Libro I de Mayordomía, 1717-1761, s. f.

${ }^{37}$ Galante Gómez, El Cristo de La Laguna..., 159.

${ }^{38}$ AESCDLL, Libro I de Mayordomía, Aumentos de Juan Mireles, 1730, s. f. la obra fue una donación realizada por el Teniente Coronel y Esclavo Mayor de dicha fecha, don Gabriel Román ${ }^{39}$.

La hermandad posee actualmente un museo que se encuentra pendiente de reorganizar para poder ser abierto al público. En este se conservan algunas de las muchas alhajas de plata que se acumularon con el paso de los siglos. La pieza más destacada es el juego de aguamanil, compuesto por fuente y jarra, con exuberantes decoraciones vegetales, tanto en la fuente como en la jarra, que incorporan un asa con forma de sirénido. Es una obra mexicana del siglo XVIII ${ }^{40}$. Del mismo siglo es el conjunto de navetas e incensario realizados en plata, ubicado por Galante Gómez en la década de los treinta de la mencionada centuria ${ }^{41}$. Hemos encontrado en los gastos realizados durante este periodo la realización de un incensario en el año 1732: "se hizo un incensario de plata, que tuvo de todo costo setecientos" ${ }^{\prime 2}$, sin embargo no se menciona la realización de las navetas. Particularmente pensamos que estas podrían corresponder a otro juego de incensarios, realizados en otro momento, y que perdieron los turíferos. En el caso del incensario tampoco se menciona la realización de este por parte del platero Juan Benítez, como indica el mencionado investigador. En el mismo año sí realizó la obra del libro de reglas, que consistió en forrar de terciopelo carmesí el libro de actas fundacional de la Esclavitud, añadiéndole las manillas de plata en las cuatro esquinas ${ }^{43}$.

${ }^{39}$ AESCDLL, Libro I de Mayordomía, Aumentos de Manuel Almeda, 1761, s. f.

40 Esta pieza ha sido ampliamente estudiada en Jesús Pérez Morera, "Platería en Canarias. Siglos XVIXIX", en Arte en Canarias [Siglos XV-XIX] Una mirada retrospectiva, com. por María Reyes Hernández Socorro (Canarias: Consejería de Educación, Cultura y Deportes, 2001), T. I, 267.

${ }^{41}$ Galante Gómez, El Cristo de La Laguna..., 165.

${ }^{42}$ AESCDLL, Libro I de Mayordomía, Aumentos de Juan Mireles, 1732, s. f.

${ }^{43}$ AESCDLL, Libro I de Mayordomía, Aumentos de Juan Mireles, 1732, s. f. 
Un patrimonio tan extenso y de tanto valor no estuvo exento de peligros, ya que tal despliegue de riquezas era el escenario perfecto para los ladrones, como sucedió en el año 1740. Una vez terminada la festividad del 14 de septiembre alguien entró en el templo y sustrajo un candelero de plata. No obstante la Esclavitud tenía por entonces suficiente solvencia económica, con la que pudo reemplazar sin demora el patrimonio perdido $^{44}$. En los convulsos años de la primera mitad del siglo XIX el patrimonio de la Esclavitud estuvo en grave peligro. Alejandro Saviñón y Anchieta, siendo mayordomo de la hermandad, asumió la responsabilidad de custodiar en su casa las alhajas del templo. En el año 1839 murió y las piezas fueron depositadas en el convento de clarisas de la ciudad, por no poder ser custodiadas en otro lugar, dado el tamaño de algunas, entre ellas el altar de plata. Estos desplazamientos tuvieron unas consecuencias nefastas para dicho patrimonio, de hecho, en el año 1848 se pagó al maestro platero Juan José de Rojas por haber desclavado todas las placas de plata del altar ${ }^{45}$, para resanarlas y colocarlas sobre nuevo soporte, dado el mal estado en el que se encontraba ${ }^{46}$. Recientemente se ha comenzado un proceso de restauración sobre estas piezas de plata y del templo; seguramente saldrán a la luz nuevos datos de gran interés con los que seguir enriqueciendo la historia del Cristo de La Laguna y de la Historia del Arte en Canarias.

${ }^{44}$ AESCDLL, Libro I de Mayordomía, Aumentos de Juan Mireles, 1740, s. f.

${ }^{45}$ Nada se sabe de este platero, no hemos encontrado más trabajos suyos en el santuario. Tampoco lo han estudiado Hernández Perera ni Rodríguez Morales. Hasta el momento esta es la primera noticia que tenemos de este maestro. Pérez Morera, "Platería en Canarias....", 369-471.

${ }^{46}$ Manuel Rodríguez Mesa, "Patrimonio artístico del Cristo de La Laguna en el siglo XIX", Anuario del Instituto de Estudios Canarios, no 44 (1999), 514.

\section{BIBLIOGRAFÍA}

Bonnet y Reverón, Buenaventura. El Santísimo Cristo de La Laguna y su culto. Santa Cruz de Tenerife: Cabildo insular de Tenerife, 1985.

Darias Príncipe, Alberto y Teresa Purriños Corbella. Arte religión y sociedad en Canarias. La Catedral de La Laguna. La Laguna: Ayuntamiento de La Laguna, 1997.

Galante Gómez, Francisco José. El Cristo de La Laguna. 500 años de historia. San Cristóbal de La Laguna: Ayuntamiento de La Laguna, 2014.

Hernández Perera, Jesús. Orfebrería en Canarias. Madrid: Instituto “Diego Velázquez CSIC, 1955.

Lorenzo Lima, Juan Alejandro. "Arquitectura, ilustración e ideal eucarístico en los templos de Canarias (1755- 1850)". Tesis Doctoral. Universidad de Granada, 2010.

Pérez Morera, Jesús. "Platería en Canarias". En Arte en Canarias [Siglos XV-XIX] Una mirada retrospectiva, comisariado por María Reyes Hernández Socorro, 241-293. Canarias: Consejería de Educación, Cultura y Deportes, 2001, Tomo I.

Pérez Morera, Jesús. "El patrimonio suntuario de la parroquia". En Patrimonio e historia de la antigua Catedral de La Laguna, coordinado por Juan Alejandro Lorenzo Lima, 45-50. San Cristóbal de La Laguna: Diócesis y Cabildo Catedral de San Cristóbal-Gobierno de Canarias-Cabildo de Tenerife-Ayuntamiento de San Cristóbal-Fundación Caja Canarias, 2013.

Rodríguez Mesa, Manuel. “Patrimonio artístico del Cristo de La Laguna en el siglo XIX". Anuario del Instituto de Estudios Canarios, $\mathrm{n}^{\mathrm{o}} 44$ (1999), 503-538.

Rodríguez Mesa, Manuel y Francisco J. Macías Martín. Materias útiles: datos para la historia de su aprovechamiento en la agricultura, el comercio y las artes de Tenerife durante los siglos XV-XVIII, la Real Sociedad Económica de Tenerife impulsadora de 
renovación y del progreso. San Cristóbal de La Laguna: Real Sociedad Económica de Amigos del País de Tenerife, 2012.

Rodríguez Morales, Carlos. Las cruces de La Laguna. Fiestas, capillas y tradición. San Cristóbal de La Laguna: Ayuntamiento de La Laguna, 2015.

Rodríguez Morales, Carlos. Todo es de plata. Las alhajas del Cristo de La Laguna. La Laguna: Ayuntamiento de San Cristóbal de
La Laguna, 2016.

Sancho de Sopranis, Hipólito. "Los conventos franciscanos de la misión de Canarias (1443-1487)". Anuario de Estudios Atlánticos, nº 5 (1959), 375-397.

Tarquis, Pedro. El Cristo de La Laguna y su santuario. La Laguna: Real y Venerable Esclavitud del Santísimo Cristo de La Laguna, 2008. 